\title{
When Peanuts Fall in Love: N400 Evidence for the Power of Discourse
}

\author{
Mante S. Nieuwland and Jos J. A. Van Berkum
}

\begin{abstract}
In linguistic theories of how sentences encode meaning, a distinction is often made between the context-free rule-based combination of lexical-semantic features of the words within a sentence ("semantics"), and the contributions made by wider context ("pragmatics"). In psycholinguistics, this distinction has led to the view that listeners initially compute a local, context-independent meaning of a phrase or sentence before relating it to the wider context. An important aspect of such a two-step perspective on interpretation is that local semantics cannot initially be overruled by global contextual factors. In two spoken-language event-related potential experiments, we tested the viability of this claim by examining whether discourse context can overrule the impact of the core lexicalsemantic feature animacy, considered to be an innate organizing principle of cognition. Two-step models of interpreta-
\end{abstract}

\section{INTRODUCTION}

During the past two decades, successful text comprehension has been equated with the construction of an adequate situation model (e.g., Zwaan \& Radvanksy, 1998; Kintsch, 1988; Johnson-Laird, 1983; Garnham, 1981), a mental representation of the state of affairs described in the text at hand. Research on situation models has shown that our narrative experiences are structured through expectations based on real-world experience with regard to time, space, causation, and so forth (see Zwaan \& Radvansky, 1998, for a review). Furthermore, neuroimaging evidence has shown that such high-level, real-world knowledge can have an immediate effect on language comprehension (e.g., Hagoort, Hald, Bastiaansen, \& Petersson, 2004; Münte, Schiltz, \& Kutas, 1998). For example, because we conceive of time in terms of a sequential order of real-world events, sentences that describe events in reverse chronological order instantly require additional discourse-level computations (Münte et al., 1998). Such findings testify to the fact that our perception and understanding of the world around us fundamentally "colors" the way we

University of Amsterdam, The Netherlands tion predict that verb-object animacy violations, as in "The girl comforted the clock," will always perturb the unfolding interpretation process, regardless of wider context. When presented in isolation, such anomalies indeed elicit a clear N400 effect, a sign of interpretive problems. However, when the anomalies were embedded in a supportive context (e.g., a girl talking to a clock about his depression), this N400 effect disappeared completely. Moreover, given a suitable discourse context (e.g., a story about an amorous peanut), animacyviolating predicates ("the peanut was in love") were actually processed more easily than canonical predicates ("the peanut was salted"). Our findings reveal that discourse context can immediately overrule local lexical-semantic violations, and therefore suggest that language comprehension does not involve an initially context-free semantic analysis.

communicate ideas and information about the world (e.g., Lakoff, 1987; Langacker, 1986).

Of course, this does not mean that the things we communicate about always need to map onto what is actually possible in the real world. Owing to the creative nature of our cognitive endowment (e.g., Fauconnier \& Turner, 2002; Pinker, 1997), we are generally able to comprehend stories that are completely at odds with the real world. Consider, for instance, Lewis Carroll's classic story of Alice's Adventures in Wonderland, in which Alice enters an absurd world with argumentative creatures, where logic and proportion are completely lost. In this and other kinds of discourse genre, fictional characters and events just do not abide by the biological or physical laws of the world as we know it, and we as readers happily accept it.

One type of world knowledge that is occasionally "violated" in a discourse such as Alice's Adventures in Wonderland is knowledge of the things that nonliving, inanimate entities can and cannot do in the real world. We know that rocks and clocks, for example, cannot be exhilarated or depressed. The animate-inanimate distinction is often considered to be a conceptual primitive, that is, an innate "building block" of cognition that has evolved under evolutionary pressures (e.g., Gelman \& Opfer, 2002; Jones, 1999; Pinker, 1997), with different 
neural mechanisms subserving each of the two categories (e.g., Caramazza \& Shelton, 1998). Yet, when we read a fairy tale or cartoonlike story in which inanimate entities act like animate ones, it is not that our language comprehension system grinds to a halt. The aim of the two studies reported below is to examine, by means of event-related potentials (ERPs), how the brain copes with stories that are internally coherent but at odds with what we know to be true in the world.

Consider reading "The girl comforted the clock" in the context of a cartoon-like story about a clock feeling depressed. How does the language comprehension system handle "comforted the clock" in this situation? In classic linguistic semantics (e.g., Katz, 1972), animacy is viewed as belonging to a set of generic semantic features (e.g., animate/inanimate, singular/plural, male/female, proximal/distal) that, because of their importance in communicating about the real world, are lexically encoded and obligatorily involved in grammatical distinctions across many languages (i.e., grammatically realized; see Jackendoff, 2002, for discussion). The assumption is that these semantic features are primitive aspects of word meaning and are recruited by linguistic-semantic computations ("semantics") that proceed more rapidly than, and independently of, computations that establish the meaning of an utterance in its wider context ("pragmatics"; e.g., Fodor, 1983; Chomsky, 1965; see Kempson, 2001, for a recent analysis of this position). Within this framework, "The girl comforted the clock" is deeply anomalous, as the inanimate "clock" is not a proper argument for the animacy-requiring "to comfort." Of course, in a final analysis where contextual pragmatics is allowed to modulate sentential semantics, the anomaly can be attenuated. However, because sentential semantics is assumed to apply before pragmatics, sentences like "The girl comforted the clock" remain initially anomalous, regardless of their wider context.

In psycholinguistics, the interplay between lexicalsemantic constraints and discourse context has been discussed in terms of "local" and "global factors" (e.g., Hess, Foss, \& Carroll, 1995), and when and how these two sources of information are recruited during discourse comprehension has been an important topic of debate (e.g., McKoon \& Ratcliff, 1998; Graesser, Millis, \& Zwaan, 1997; Carpenter, Miyake, \& Just, 1995). Echoing the linguistic distinction between semantics and pragmatics, some models of language comprehension assume that people compute a local, context-independent meaning of a phrase or sentence before integrating it in the prior discourse (e.g., Millis \& Just, 1994; Kintsch, 1988; Fodor, 1983, Forster, 1979). According to such "two-step" models of interpretation, local semantics can initially not be overruled by global contextual factors, and sentences like "The girl comforted the clock" should thus invariably perturb the comprehension system, regardless of context.
This assumption about the temporal and functional distinction between local and global effects has been challenged by more interactive models of language comprehension (e.g., Jackendoff, 2002; MacDonald, Pearlmutter, \& Seidenberg, 1994; Trueswell \& Tanenhaus, 1994; Bates \& MacWhinney, 1989; Marlsen-Wilson \& Tyler, 1980). The general tenet of these "single-step" models of language interpretation is that locally supplied "semantic" cues have no principled temporal or functional precedence over globally supplied "pragmatic" cues. Because both types of constraint can simultaneously determine language interpretation and can in principle overrule each other as a function of cue relevance and strength, a sentence like "The girl comforted the clock" may in certain discourse contexts actually be very easy to interpret. ${ }^{1}$

With classic psycholinguistic paradigms (e.g., crossmodal naming or lexical decision, eye tracking during reading) it has been difficult to resolve the issue of when and how local and global factors interact in comprehension, with some findings suggesting a relatively late influence of prior discourse on lexical or phrase processing (e.g., Millis \& Just, 1994; Rayner, Pacht, \& Duffy, 1994; Till, Mross, \& Kintsch, 1988) and others revealing an early impact of discourse-level conceptual information (e.g., Hess, et al., 1995; Marslen-Wilson \& Tyler, 1980). With the recent addition of the "visual world" or "head-mounted" eye-tracking paradigm to the psycholinguist's methodological repertoire, the evidence that extrasentential context can very rapidly affect word and sentence comprehension is steadily accumulating (e.g., Altmann \& Kamide, 1999; Tanenhaus, Spivey-Knowlton, Eberhard, \& Sedivy, 1995; see Trueswell \& Tanenhaus, 2005, for many more examples). However, none of these studies has examined the interaction of global discourse context with a local, "primitive" semantic feature as fundamental and powerful as animacy. Furthermore, the various processing measures discussed so far (RT, fixation times) do not by themselves provide qualitative information as to whether in language comprehension, local and global factors are processed by the same single brain system or, alternatively, by two functionally distinct brain systems.

In the experiments reported below, we track the interplay between global discourse-level factors and local animacy constraints by means of ERPs, a highly timeresolved measure that does intrinsically provide cues to the identity of the cognitive event at hand (e.g., Van Berkum, 2004; Rugg \& Coles, 1995). The most commonly used ERP index of semantic processing is the N400, a centroparietally distributed, negative ERP deflection that peaks at approximately $400 \mathrm{msec}$ after word onset (Kutas \& Hillyard, 1980). The N400 is elicited by every content word of an unfolding sentence, and its amplitude is inversely related to the ease with which the word at hand is related to its semantic context (e.g., Brown, Hagoort, \& Kutas, 2000; Kutas \& Van Petten, 1994, for a review). For example, words that do not 
easily fit the animacy requirements imposed by a sentential context elicit a larger N400 than words that do fit those requirements (e.g., Weckerly \& Kutas, 1999; see also Trueswell, Tanenhaus, \& Garnsey, 1994, for eyemovement evidence for immediate effects of animacy on ambiguity resolution). The N400 is also highly sensitive to how well the words of an unfolding sentence fit the wider discourse (e.g., Van Berkum, Brown, Zwitserlood, Kooijman, \& Hagoort, 2005; Van Berkum, Zwitserlood, Hagoort, \& Brown, 2003; Van Berkum, Hagoort, \& Brown, 1999; Van Petten, 1995; St. George, Mannes, \& Hoffman, 1994, 1997). Because of its established sensitivity to locally supplied animacy requirements as well as discourse-level global context, the N400 component allows us to examine the interplay between the two.

The few studies that have examined the sensitivity of the N400 to discourse-level manipulations (see Van Berkum, in press, for a review) suggest a temporal and functional equivalence of local and global semantic context, as predicted by a single-step model of language interpretation. St. George et al. (1994), for example, observed that adding a title to a paragraph to increase its coherence led to smaller N400 components elicited by the words in that paragraph. Because the resulting discourse-level N400 effect emerged at about the same time as the N400 effects that had been reported for more local semantic manipulations, this finding suggested that discourse-level factors are brought to bear on comprehension as rapidly as local factors. Systematic comparisons of discourse- and sentence-dependent anomalies within the same experimental paradigm (Van Berkum, Zwitserlood, et al., 2003; Van Berkum, Hagoort, et al., 1999) confirmed that the two anomalies elicit essentially identical N400 effects, sharing their time course, overall morphology, and scalp distribution. In addition, follow-up work revealed that the N400 is not only sensitive to blunt discourse-dependent anomalies, but can reflect much more subtle differences in discourse-level fit (e.g., Otten \& Van Berkum, 2005; Van Berkum, Brown, et al., 2005).

In all, these N400 findings suggest that, from the perspective of the language comprehension system, it does not matter whether its constraints on interpretation come from local sentence internal context or from wider discourse context. Elsewhere (e.g., Van Berkum, Zwitserlood, et al., 2003; Van Berkum, Hagoort, et al., 1999), we have taken this as evidence that the words of an unfolding sentence are immediately mapped onto the widest interpretive domain available (one-step interpretation) and that there is no initial computation of local context-free meaning followed by contextual reappraisal (two-step interpretation). However, a much more direct way to demonstrate this would be to pit local and global semantic factors against one another and show that even a powerful, local semantic anomaly can be completely neutralized by a discourse context.
This was the purpose of the two ERP experiments reported below.

In our first experiment, participants listened to short narratives in which a person was engaged in conversation with either another person or with an inanimate object (see Table 1). In the latter case, we expected the narrative to gradually and implicitly set up a cartoonlike interpretive context for our subjects, that is, a context in which it is not uncommon for inanimate objects to have animate properties. The issue was whether and at what point in the story this wider pragmatic context, once in place, would be able to overrule a local semantic anomaly. Subjects encountered comparable animacy violations in the first, third, and fifth sentence of the inanimate story (e.g., "The therapist consoled the yacht"). We expected the violation in the first sentence to elicit a standard N400 effect compared to the animate control words. The critical issue was whether the gradual build-up of a cartoonlike context would be able to eliminate the interpretive problems posed by animacy violations somewhat later in the story, in the third or fifth sentence. If it can indeed do so, as predicted by single-step models of interpretation, those later animacy violations should not elicit an $\mathrm{N} 400$ effect. If the initial interpretation is governed by local lexical-semantic factors only, however, an N400 effect should also still be obtained toward the end of the story.

\section{EXPERIMENT 1}

\section{Methods}

\section{Subjects}

Thirty-one right-handed college students (14 men, mean age 21.8) participated in this study for course credit. All participants were native speakers of Dutch and without any neurological impairment.

Table 1. Example Story (Approximate Translation from Dutch)

1. Once upon a time, a psychotherapist was consulted in her home office by a yacht/sailor with emotional problems.

2. The yacht/sailor confided in her that everything in life had gone wrong and started crying

3. The psychotherapist consoled the yacht/sailor by stating that everybody experiences these kinds of trouble every now and then.

4. But the yacht/sailor doubted whether to continue outlining his problems to her.

5. The psychotherapist advised the yacht/sailor to be honest not only with her, but especially with himself.

6. At that moment the yacht/sailor cried out that he was absolutely terrified of water. 


\section{Materials}

We constructed 60 naturally spoken Dutch stories. To allow us to record the EEG without an attention-recruiting and potentially biasing secondary task (see Van Berkum, 2004), we designed these stories to be as engaging as possible under the constraints of the present design. Each story consisted of six sentences and contained two different main entities. One entity was always a woman, the other was always either a man (animate condition) or an inanimate object (inanimate condition).

Every sentence contained a noun phrase anaphor to either the man or the inanimate object. Stories in both conditions were identical except for the critical words (CWs) denoting the men and inanimate objects. The CWs were closely matched for word duration (mean 566 and $580 \mathrm{msec}$, respectively) and word form frequency (mean 1.78 and 1.75 on a million; Spoken Dutch Corpus). As can be seen in Table 1 , in the inanimate condition every sentence contained an animacy violation. For the analyses, however, we focus on the first, third and fifth sentence of every story, each of which contained a highly comparable mismatch between requirements imposed by the transitive verb and the inanimate argument actually supplied to this verb (i.e., a selection restriction violation). For each story an animate and inanimate version were recorded with a normal speaking rate and intonation by the same female speaker.

\section{Procedure}

Participants were seated in front of two loudspeakers and were informed that they would be listening to short stories. They were instructed to listen for comprehension and minimize movement. No additional task demands were imposed.

Two trial lists were used. For the first list, 30 animate context and 30 inanimate context stories were pseudorandomly mixed with 90 filler stories such that neither cartoon trials nor control trials occurred more than twice consecutively and trials of each type were matched on average list position. The second list was derived from the first by replacing all cartoon trials by their control counterparts and vice versa. The 90 filler stories described scenarios about three human characters engaged in conversation, 30 of which contained temporarily referentially ambiguous noun phrases. The total of 150 stories was divided into 10 blocks separated by a pause. Each trial was separated from the next by a 5-sec silence and was preceded by a short warning tone. Total time-on-task was approximately $80 \mathrm{~min}$.

\section{EEG Recording}

The EEG was recorded from 30 standard scalp locations (Fz, Cz, Pz, Oz, Fp1/2, F3/4, F7/8, F9/10, FC1/2, FC5/6, FT9/10, C3/4, T7/8, CP1/2, CP5/6, P3/4, P7/8), amplified (band-pass filtered at $0.03-100 \mathrm{~Hz}$ ), digitized at $500 \mathrm{~Hz}$, and re-referenced to the mean of left and right mastoids. Ocular and muscular artifacts were corrected by means of a procedure based on independent component analysis (see Jung et al., 2000; Makeig, Jung, Gahremani, Bell, \& Sejnowski, 1997). Then, epochs that ranged from -500 to $+1600 \mathrm{msec}$ relative to critical word onset were extracted and normalized (by subtraction) to a 150 -msec pre-onset baseline. Subsequently, segments with potentials exceeding $\pm 75 \mu \mathrm{V}$ were rejected, and the remainder was screened for drift artifacts. If the total rejection rate exceeded $40 \%$, data of the participant were excluded. Seven participants were excluded from Experiment 1, leaving an average segment loss of $15 \%$ across the remaining 24 participants.

\section{Results}

The grand average waveforms elicited by the inanimate ("yacht") and animate ("sailor") critical words in the first, third, and fifth sentence are displayed in Figures 1, 2 , and 3, respectively. As expected, inanimate nouns elicited a larger N400 than animate control nouns in the first sentence. Using mean amplitude in the 300- to 600-msec time window, this N400 effect was significant in an overall 2 (animacy) $\times 30$ (electrode) analysis of variance (ANOVA; see Table 2). More importantly, there were no significant differences between ERPs elicited by the same inanimate and animate critical words either in the third or fifth sentence.

We also examined whether the violation-preceding verbs (such as "consoled" and "advised" in the third and fifth sentence, respectively), which always formally required an animate object, would elicit any differential effects of whether the wider discourse did or did not involve conversation with inanimate objects. Surprisingly, in the third sentence these verbs elicited an N400 effect in inanimate story context, compared to identical verbs in the animate story context (Figure 4). This effect was only trendwise significant in the 300- to 600-msec time window, $F(1,23)=3.58, M S E=24.35, p=.071$, but was statistically significant in the $400-700 \mathrm{msec}$ mean amplitude time window, $F(1,23)=4.56, M S E=22.73$, $p=.044$. In the fifth sentence, this effect had disappeared (Figure 5), as was confirmed by analysis of both the 300-600 msec, $F(1,23)=0.02, M S E=29.11, p=.879$, and 400-700 msec, $F(1,23)=0.004, M S E=34.34$, $p=.950$, time window.

\section{Discussion}

In Experiment 1 we investigated whether a cartoonlike discourse context would be able to prevent the language comprehension system from being disrupted by a local animacy violation. According to two-step models of language comprehension, which assume that local semantic factors have a functional and temporal precedence 
Figure 1. Grand-average ERPs elicited by critical nouns in the first sentence (Experiment 1). In this and all following figures, ERPs elicited by critical words in the Inanimate conditions are represented by dotted lines, whereas ERPs elicited by critical words in the Animate conditions are represented by solid lines. Furthermore, all waveforms are filtered $(5-\mathrm{Hz}$ high cutoff, $48 \mathrm{~dB} / \mathrm{oct}$ ) for presentation purposes only, negativity is plotted upwards, and the scalp distribution of the Animacy effect (Inanimate condition minus Animate condition, mean amplitude in the 300 to 600 msec time window) is displayed in the lower right corner.

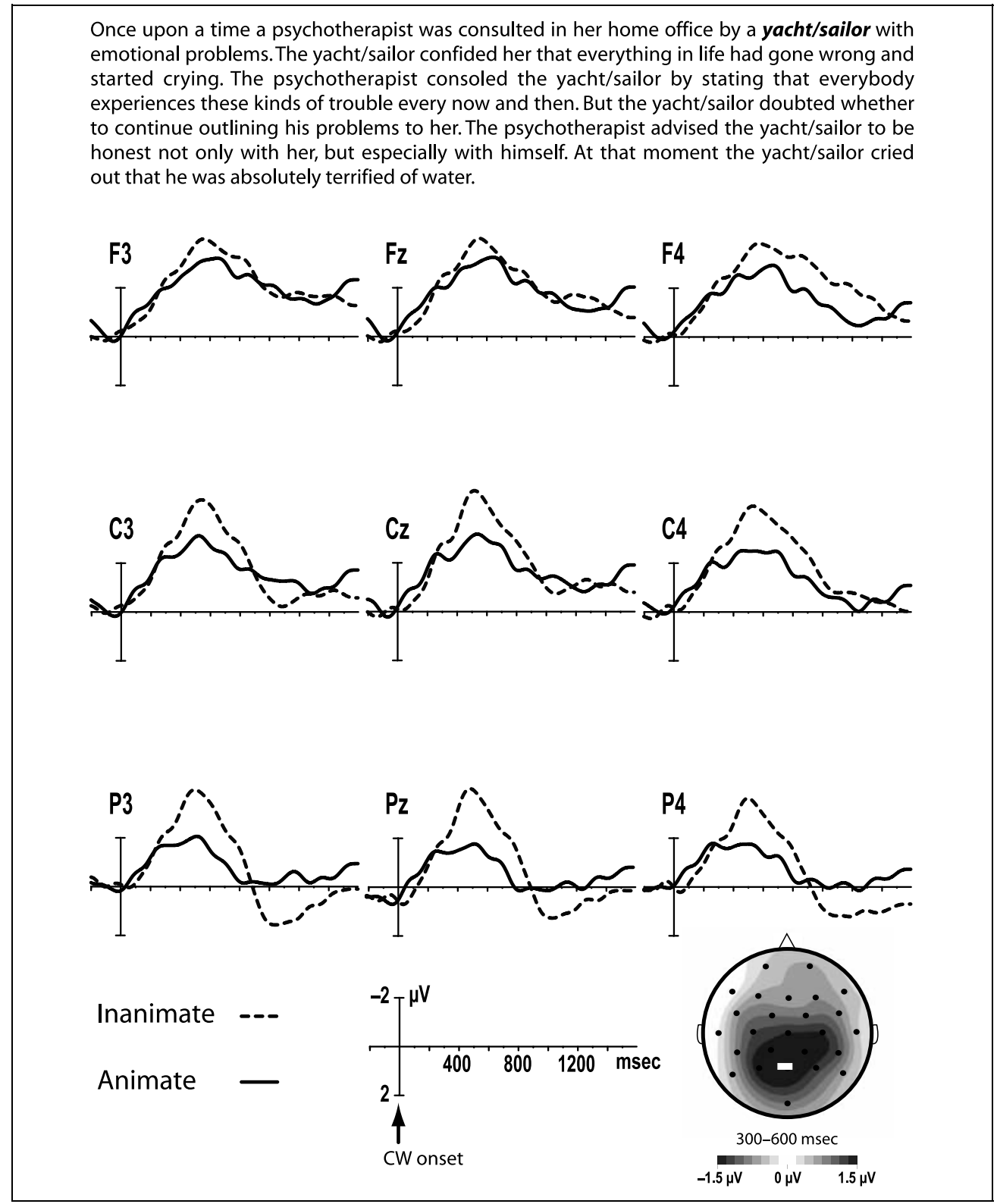

over global discourse context (e.g., Millis \& Just, 1994; Kintsch, 1988; Fodor, 1983), animacy violations should always disrupt semantic processing regardless of context. Alternatively, if discourse-level and local animacy constraints are simultaneously brought to bear on language comprehension in a fundamentally equivalent way (e.g., Van Berkum, Hagoort, et al., 1999; Clark, 1996; Gibbs, 1984), a sufficiently strong discourse context should be able to completely overrule the impact of local, lexical-semantic factors. Our results lend support to the latter one-step model: Whereas animacy violation in the first sentence elicited a large N400 effect, no such effect was elicited by comparable animacy violations encountered later in the story. These results suggest that a cartoonlike interpretive context, in which it is not uncommon for specific inanimate objects to behave just like human beings, can-once in place-completely overrule the effect of a local lexical-semantic animacy violation.

An interesting extension of these results followed from the examination of the ERPs elicited by the violation-preceding verbs in the third and fifth sentence (e.g., consoled and advised, respectively). To create a local animacy violation on the critical inanimate object noun thereafter, we used verbs that always formally required an animate object. In the third sentence of inanimate stories, however, these verbs also elicited a small N400 effect (relative to the same verbs in animate stories). In the fifth sentence, this verb-elicited N400 effect had again disappeared. We interpret this effect to suggest, first, that listeners begin to look for plausible arguments of a verb right upon encountering the verb itself, a finding that is consistent with evidence for scene-based anticipation of verb arguments (e.g., Altmann \& Kamide, 
Figure 2. Grand-average ERPs elicited by critical nouns in the third sentence (Experiment 1).
Once upon a time a psychotherapist was consulted in her home office by a yacht/sailor with emotional problems. The yacht/sailor confided her that everything in life had gone wrong and started crying. The psychotherapist consoled the yacht/sailor by stating that everybody experiences these kinds of trouble every now and then. But the yacht/sailor doubted whether to continue outlining his problems to her. The psychotherapist advised the yacht/sailor to be honest not only with her, but especially with himself. At that moment the yacht/sailor cried out that he was absolutely terrified of water.
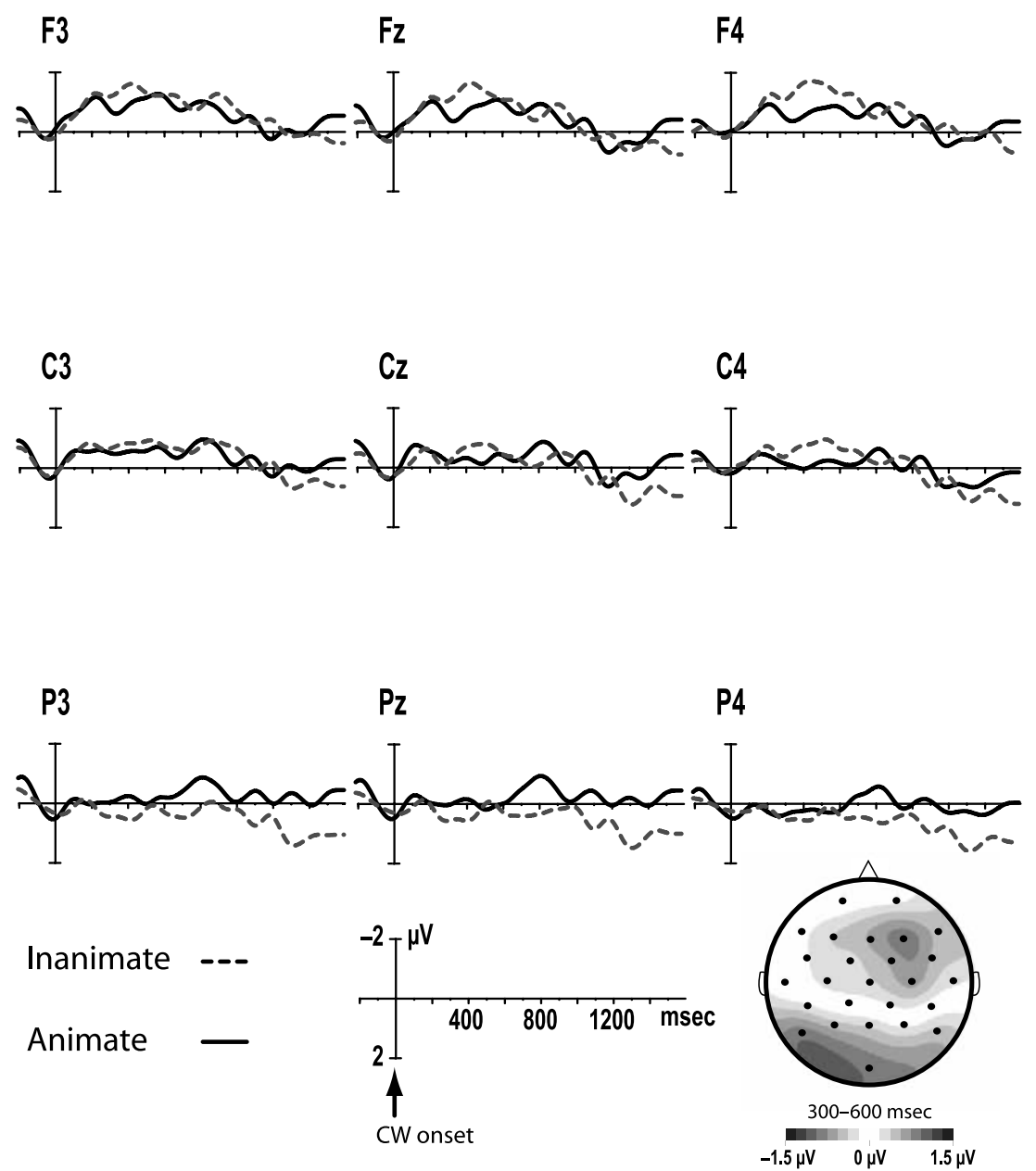

1999; Sedivy, Tanenhaus, Chambers, \& Carlson, 1999), as well as with other ERP effects of discourse-based predictive processes (e.g., Van Berkum, Brown, et al., 2005; Wicha, Bates, Moreno, \& Kutas, 2003). Furthermore, a verb-elicited N400 effect in the third sentence reveals that at that point in the story, the discourse model is not yet strong enough to completely overrule the anticipated local anomaly. Apparently, although listeners did anticipate the inanimate objects as upcoming verb arguments, they did not yet at this point accept them as completely suitable referents.

We take the absence of an N400 effect at both the verb and noun in the fifth sentence to suggest that, ultimately, a strong discourse context can indeed completely overrule local lexical-semantic animacy violations. However, two alternative explanations for the decline of the N400 effect observed in this experiment need to be addressed. First, one might argue that this decline is solely the result of simple lexical repetition. We consider this somewhat implausible, as this argument entails that the more often we encounter a word, the more difficult it is for us to notice that it is used erroneously. Note that mistakes in, say, using "a" versus "an" or in using "he" instead of "she" do not easily escape attention in spite of the massive repetition of these words. Such a lexical repetition account also cannot explain why the N400 effect observed at the violation-preceding verb in the third sentence was subsequently absent at a lexically different verb in the fifth sentence. Alternatively, one might argue that the disappearance of the N400 effect was caused by our subjects becoming indifferent (i.e., "tuning out") during cartoonlike stories, possibly due 
Figure 3. Grand-average ERPs elicited by critical nouns in the fifth sentence (Experiment 1).
Once upon a time a psychotherapist was consulted in her home office by a yacht/sailor with emotional problems. The yacht/sailor confided her that everything in life had gone wrong and started crying. The psychotherapist consoled the yacht/sailor by stating that everybody experiences these kinds of trouble every now and then. But the yacht/sailor doubted whether to continue outlining his problems to her. The psychotherapist advised the yacht/sailor to be honest not only with her, but especially with himself. At that moment the yacht/sailor cried out that he was absolutely terrified of water.
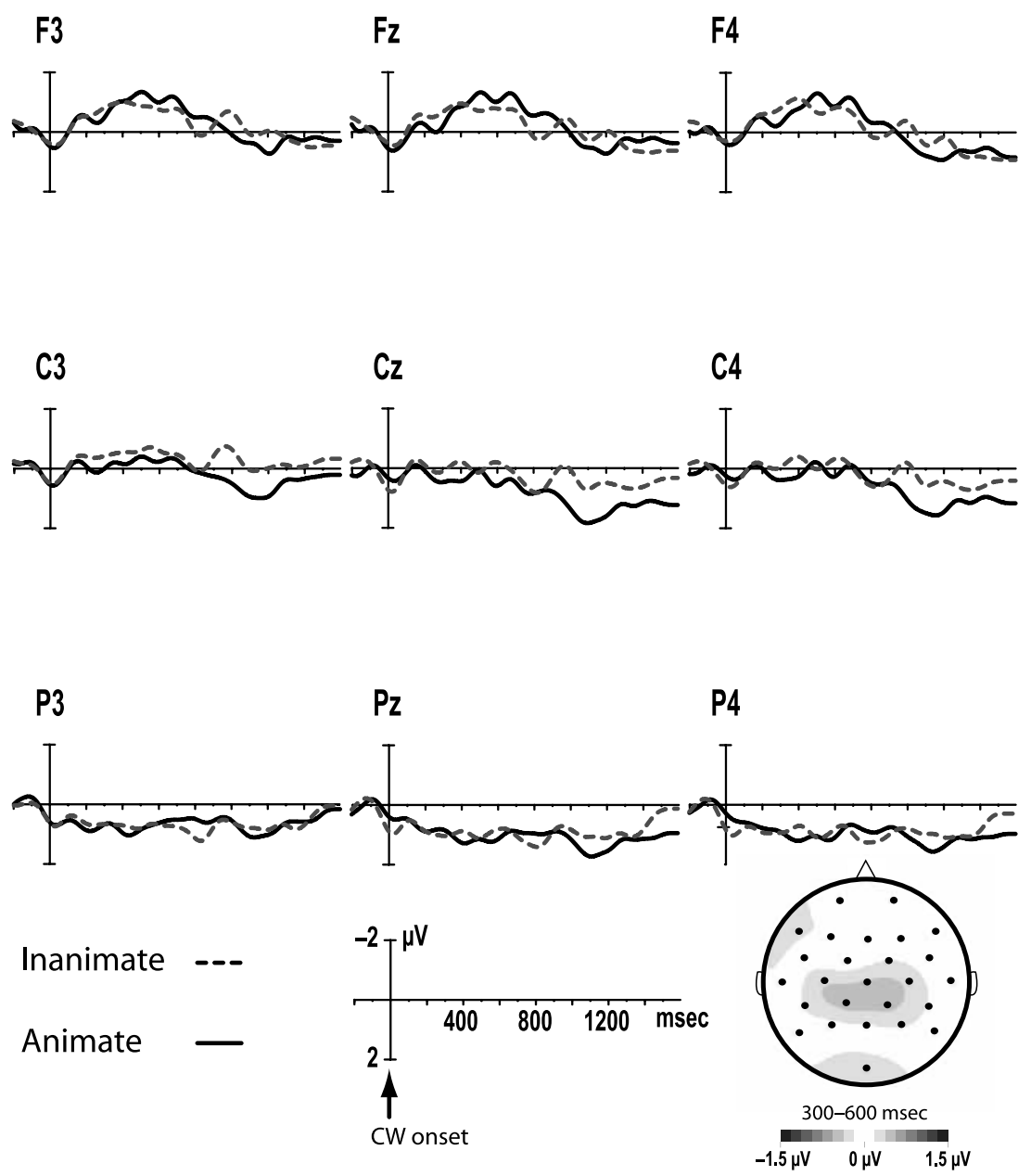

to incomprehensible or unrealistic content. This explanation also seems unlikely, though, for in the systematic exit-interview held after the experiment all our subjects reported that they found our cartoonlike

Table 2. $F$ Values, Mean Square Errors (MSE) and $p$ Values for Main Effects of Animacy Time-locked to Critical Word Onset

\begin{tabular}{lccc}
\hline & $F$ & $M S E$ & $p$ \\
\hline Sentence 1 & 5.82 & 37.23 & $.024^{*}$ \\
Sentence 3 & 0.19 & 30.44 & .667 \\
Sentence 5 & 0.95 & 21.12 & .761 \\
\hline
\end{tabular}

For all $F$ tests, numerator $d f=1$, denominator $d f=23$.

$* p<.05$. stories easy to grasp and entertaining. In all, we ascribe the results from Experiment 1 to the fact that a cartoonlike story gradually provided a wider interpretive context that "neutralized" the violation of animacy requirements. In our second experiment, we generalize and extend this finding, and provide further evidence against the above-mentioned lexical repetition and tuning out accounts.

\section{EXPERIMENT 2}

In Experiment 2, we examined whether a cartoonlike interpretive context can go beyond just neutralizing the potentially harmful impact of an animacy violation and can actually outweigh the joint effects of animacy and real-world plausibility. In this experiment, all critical stories were cartoonlike stories, for instance, about a 
Figure 4. Grand-average ERPs elicited by critical verbs in the third sentence (Experiment 1).
Once upon a time a psychotherapist was consulted in her home office by a yacht/sailor with emotional problems. The yacht/sailor confided her that everything in life had gone wrong and started crying. The psychotherapist consoled the yacht/sailor by stating that everybody experiences these kinds of trouble every now and then. But the yacht/sailor doubted whether to continue outlining his problems to her. The psychotherapist advised the yacht/sailor to be honest not only with her, but especially with himself. At that moment the yacht/sailor cried out that he was absolutely terrified of water.
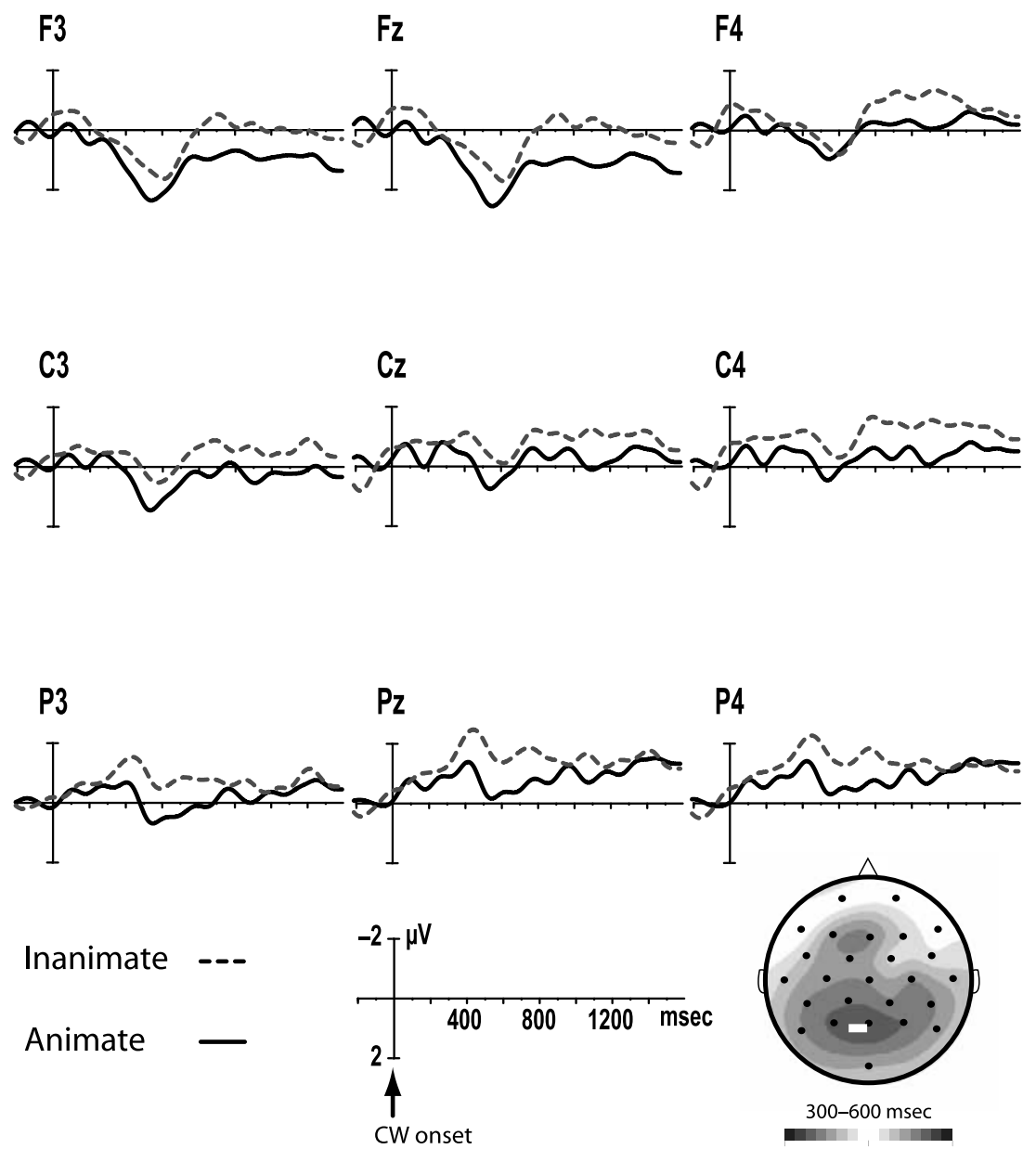

P4
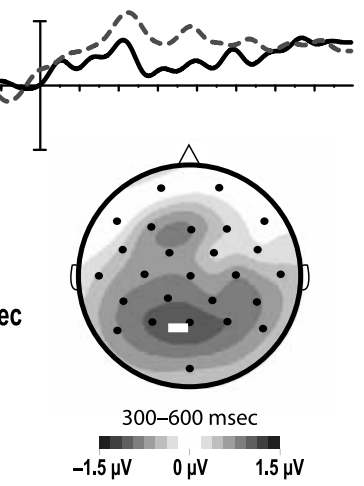

peanut and his new girlfriend (see Table 3). Towards the end of these stories, the inanimate object was described either with a context-appropriate but animacy-violating property (e.g., "The peanut was in love" in a story about a peanut singing a song about his new girlfriend) or with an inanimate property that was "canonical" for the object but highly inappropriate in this particular context (e.g., "The peanut was salted").

The experimental logic of this experiment was similar to that of Experiment 1. In a two-step model of semantic interpretation, initial semantic processing is governed by local semantic factors, and only its outcome is related to the global discourse context. Under such a model, locally anomalous but contextually appropriate predicates (e.g., "in love") should elicit an N400 effect compared to locally plausible but contextu- ally inappropriate predicates (e.g., "salted"). A singlestep model, in which locally and globally supplied information can both immediately affect semantic processing, predicts exactly the reverse pattern. If discourse context prevails over animacy and real-world plausibility taken together, locally plausible but contextually inappropriate predicates should elicit an N400 effect compared to locally anomalous but contextually appropriate predicates.

\section{Methods}

\section{Subjects}

Forty-two right-handed college students (10 men, mean age 20.7 years) participated in this study for course 
Figure 5. Grand-average ERPs elicited by critical verbs in the fifth sentence (Experiment 1).
Once upon a time a psychotherapist was consulted in her home office by a yacht/sailor with emotional problems. The yacht/sailor confided her that everything in life had gone wrong and started crying. The psychotherapist consoled the yacht/sailor by stating that everybody experiences these kinds of trouble every now and then. But the yacht/sailor doubted whether to continue outlining his problems to her. The psychotherapist advised the yacht/sailor to be honest not only with her, but especially with himself. At that moment the yacht/sailor cried out that he was absolutely terrified of water.

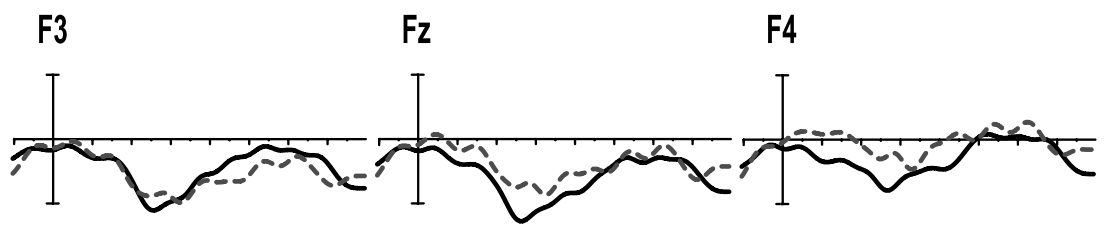

$\begin{array}{lll}\mathrm{C} 3 & \mathrm{Cz} & \mathrm{C} 4\end{array}$

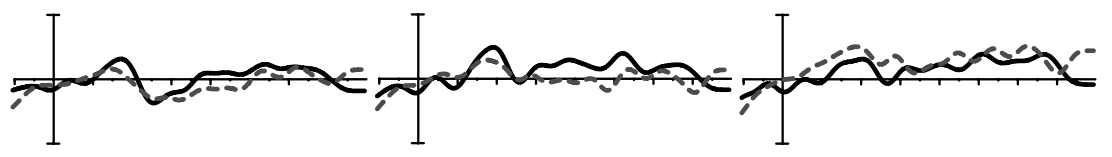

P3 Pz P4
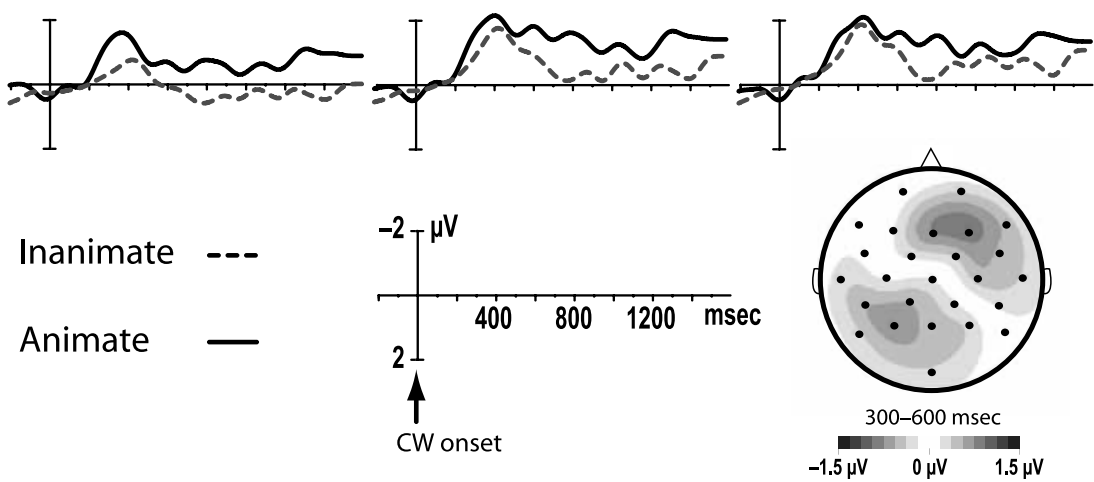

credit. All participants were native speakers of Dutch and without any neurological impairment.

\section{Materials}

Participants listened to 60 naturally spoken Dutch, cartoonlike stories. Each story consisted of six sentences and contained two different main entities, one woman and one inanimate object that behaved as a human character. A difference between the two conditions emerged only in the fifth sentence. Either the inanimate object was described with a canonical, but story-irrelevant inanimate property (inanimate condition), or with a formally anomalous but contextually appropriate animate predicate (animate condition). These predicates consisted of adjectives that were closely matched for word duration (mean 552 and $556 \mathrm{msec}$, respectively) and word form frequency (mean 1.26 and 1.29 on a million; Spoken Dutch Corpus). As in Experiment 1, the same female speaker recorded all stories with a normal speaking rate and intonation.

Table 3. Example Story (Approximate Translation from Dutch)

A woman saw a dancing peanut who had a big smile on his face. The peanut was singing about a girl he had just met. And judging from the song, the peanut was totally crazy about her. The woman thought it was really cute to see the peanut singing and dancing like that. The peanut was salted/ in love, and by the sound of it, this was definitely mutual. He was seeing a little almond. 


\section{Procedure}

The procedure of Experiment 2 was identical to that of Experiment 1, with the following exceptions pertaining to presentation modality and filler materials.

In contrast to Experiment 1, in which the stories were completely presented in the auditory modality, the noncritical story-final sentences were presented in variable serial visual presentation mode (RSVP) based on natural reading times. This was done to increase the homogeneity of our material, as the filler stories contained visually presented story-final sentences. The epochs that were extracted for subsequent analysis always fell within the time range of the last auditorily presented sentence.

For the first list, 30 incoherent and 30 coherent stories were pseudorandomly mixed with 90 filler stories (of which the first two sentences were spoken, and the final sentence was presented in VSVP mode) and 120 isolated sentences (all presented in VSVP mode). The 90 filler stories described scenarios about three human characters engaged in conversation, 30 of which contained referentially ambiguous noun phrases in the final sentence. Of the 120 isolated sentences, 60 described the location of various manipulable objects, and 60 described a person manipulating one of these objects.

The total of 150 stories and 120 isolated sentences was divided into five blocks separated by a pause. Each trial was separated from the next by a 4-sec silence and was preceded by a short warning tone. Total time-on-task was approximately $70 \mathrm{~min}$.

\section{EEG Recording}

The EEG was recorded and processed identically to Experiment 1. In Experiment 2, none of the participants met the exclusion criteria regarding rejection rates of artifactual epochs, and there was an average segment loss of $8 \%$.

\section{Results}

The grand average waveforms elicited by locally plausible but contextually inappropriate (salted) and locally anomalous but contextually appropriate predicates (in love) are displayed in Figure 6. Predicates that were canonical for a particular object but inappropriate given the discourse context elicited an N400 effect compared to formally anomalous but contextually appropriate predicates.

Using as mean amplitude the 300- to 600-msec time window, this $\mathrm{N} 400$ effect was significant in an overall 2 (animacy) $\times 30$ (electrode) ANOVA, $F(1,41)=27.14$, $M S E=27.57, p=.001$.

\section{Discussion}

The goal of Experiment 2 was to examine whether context appropriateness can outweigh the joint effects of animacy and real-world plausibility. Subjects listened to cartoonlike stories in which inanimate objects (e.g., a peanut) were characterized either with a canonical but context-inappropriate predicate (e.g., salted), or with a semantically anomalous but contextually appropriate predicate (e.g., in love). Inconsistent with two-step models of semantic interpretation but in line with single-step models, locally plausible but contextually inappropriate predicates elicited a larger N400 than locally anomalous predicates that fitted the wider discourse context. These results extend our findings from Experiment 1, as they show that contextual appropriateness not only can "neutralize" animacy violations, but can even render the animacy-violating predicate more preferred than an animacy-obeying canonical predicate.

Note that the present results cannot be explained by a lexical repetition confound, as both critical words (e.g., salted, in love) were used for the first time in the story at hand. Furthermore, the present findings unequivocally indicate that the results from Experiment 1 cannot be attributed to subjects tuning out during "odd" stories. After all, toward the end of the equally odd stories in Experiment 2, subjects had no trouble whatsoever detecting a discourse-level semantic anomaly.

\section{GENERAL DISCUSSION}

We conducted two ERP experiments to examine whether discourse context could modulate the semantic interpretive processes revolving the animacy of fictional entities. Subjects listened to naturally spoken (Dutch) cartoonlike stories describing conversational interactions between human characters and inanimate objects. In Experiment 1, inanimate nouns in story-initial sentences like "The girl comforted the clock" elicited an N400 effect compared to animate control words, reflecting the fact that in the absence of a wider interpretive context, listeners find it odd to encounter inanimate objects engaged in conversation. Furthermore, verbs that preceded the animacy violations in the third sentence and that formally required animate objects, elicited an N400 effect in inanimate story context, compared to identical verbs in animate story context. This effect not only suggests that listeners can use their model of the discourse to anticipate specific arguments of a given verb, but also that the discourse model at that point is not yet strong enough to overrule the anticipated local anomaly. The most critical finding of this experiment, the absence of an N400 effect at both the verb and noun in the fifth sentence, suggests that ultimately, a strong discourse model can indeed completely neutralize a 
Figure 6. Grand-average ERPs elicited by critical predicates in the fifth sentence (Experiment 2).
A woman saw a dancing peanut who had a big smile on his face. The peanut was singing about a girl he had just met. And judging from the song, the peanut was totally crazy about her. The woman thought it was really cute to see the peanut singing and dancing like that. The peanut was salted/in love, and by the sound of it, this was definitely mutual. He was seeing a little almond.
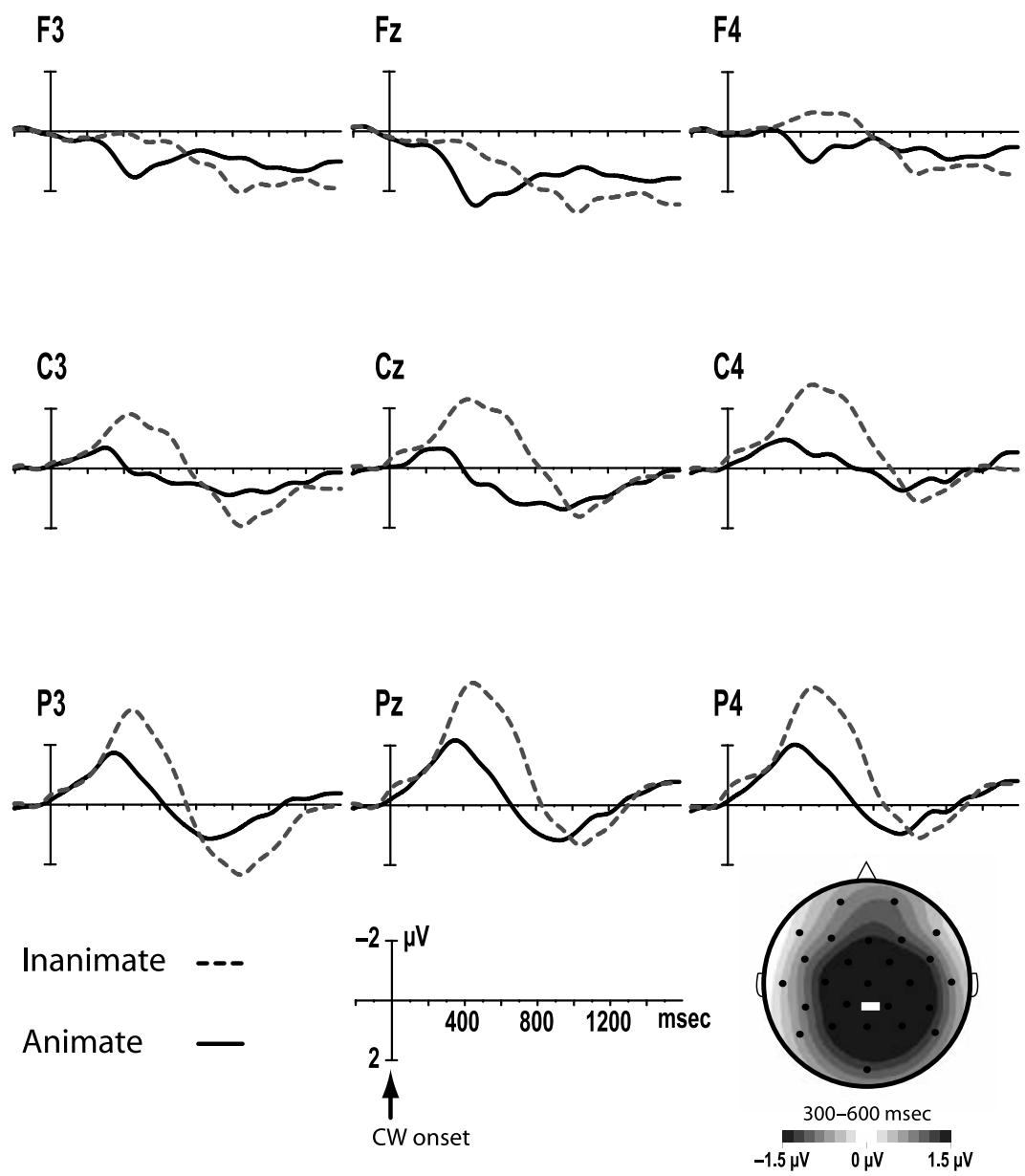

local animacy violation. Finally, in Experiment 2, inanimate predicates that were canonical for inanimate objects but inappropriate given the discourse context (e.g., a peanut being salted), elicited an N400 effect when assigned to these objects, compared to locally anomalous but contextually appropriate predicates (e.g., a peanut being in love). This last finding suggests that the results from Experiment 1 cannot be attributed to possible "tuning out" of the subjects during unrealistic stories nor to the effects of lexical repetition. But, more importantly, it suggests that contextual appropriateness not only "neutralizes" processing difficulties that are introduced by animacy violations but can actually even outweigh the joint effects of animacy and real-world plausibility.

Taken together, the results of our experiments constitute strong evidence that discourse context can completely overrule lexical-semantic violations. As such, they support interactive, "single-step" models of language comprehension, in which local and global context can both immediately influence interpretation, without giving principled precedence to local semantic information (e.g., Jackendoff, 2002; MacDonald et al., 1994; Trueswell \& Tanenhaus, 1994; Bates \& MacWhinney, 1989; Marlsen-Wilson \& Tyler, 1980). Our findings also indirectly support the perspective on language structure that is usually behind those single-step models of comprehension, one that does not make a sharp distinction between linguistic semantics (i.e., linguistic knowledge about the core meaning of words) and pragmatics (i.e., knowledge about how we use these words in everyday language; e.g., Jackendoff, 2002; Kempson, 2001; Clark, 1996; Gibbs, 1984). Furthermore, our findings accord well with a growing number of other observations that discourse context is immediately brought to bear on language comprehension (e.g., Altmann \& Kamide, 1999; Van Berkum, Hagoort, et al., 1999; Hess et al., 1995; St. George et al., 1994; Marslen-Wilson \& Tyler, 1980; see Van Berkum, in press, for a review of the ERP evidence). 
At this point, we should briefly clarify the relation between our present findings and those reported in Nieuwland and Van Berkum (2005). What we observed in the latter study with realistic noncartoon stories is that under certain "misleading" conditions that are known to lead to incorrect semantic analyses of the input-"semantic illusions"-in behavioral experiments, highly unexpected animacy violations do not elicit an N400 effect. As explained in detail in Nieuwland and Van Berkum, we took this result to indicate that the listeners in this experiment momentarily suffered from a semantic illusion, and briefly failed to notice that the by then familiar animate protagonist was suddenly replaced by an inanimate object (akin to the so-called change blindness phenomenon in visual perception). Our explanation of the present results, however, has nothing to do with momentarily erroneous analyses and semantic illusions, and instead capitalizes on the speed and flexibility with which the comprehension system can arrive at a correct interpretation in nonmisleading situations. What binds the two sets of findings is that they both testify to the power of prior discourse in guiding the initial interpretation of unfolding input and to conspire with other factors such that a superficially anomalous critical word is easily integrated (albeit erroneously in the semantic illusion case). ${ }^{2}$

In all, we take the disappearance of an N400 effect in Experiment 1 to show that even a semantic anomaly revolving around a core semantic feature like animacy, can effortlessly be integrated into a prior discourse, if this discourse has provided a context in which it is not uncommon for a particular inanimate object to have animate properties. We take the results from Experiment 2 to illustrate that it sometimes may be easier to integrate a lexical-semantic anomaly that is globally coherent than a "correct" phrase that is plausible with regard to real-world knowledge but that has nothing to do with the prior discourse.

Given the present findings, we should offer a speculative remark on what it might really "mean" to understand a story about, for example, a peanut that has fallen in love. Interestingly, although subjects had no instructions other than to listen for comprehension, almost all of them reported to have interpreted the inanimate objects in our stories as actual "cartoon-character-like" entities (i.e., a peanut that walks and talks like a human, having emotions and possibly even arms, legs, and a face). ${ }^{3}$ To achieve such an interpretation, listeners need to construct and gradually update their situation model of the story to the point that they project human characteristics onto inanimate objects (e.g., Zwaan \& Radvansky, 1998). This process of projecting human properties (behavior, emotions, appearance) onto an inanimate object comes close to what has been called "conceptual blending," the ability to invent new concepts and to assemble new and dynamic mental patterns by "blending" elements and vital relations from diverse scenarios (e.g., Fauconnier \& Turner, 2002). Furthermore, most subjects also indicated that they visualized the cartoonlike stories in order to comprehend them, which seems to illustrate the importance of perceptual processes in cognitive mechanisms like language and memory (e.g., Barsalou, 1999). Within such a framework, projecting animate properties onto an inanimate object might perhaps even be understood as "perceptual blending" during language comprehension. Regardless of representational concerns, however, we assume that the acceptability of a crying yacht or amorous peanut is not merely induced by repeated specific instances of such unusual feature combinations, but somehow alsoperhaps even critically-by the literary genre (e.g., Zwaan, 1994) that such instances suggest.

The fact that listeners had no trouble whatsoever comprehending our cartoonlike stories suggests that they can temporarily "bracket" their real-world knowledge of the distinction between living and nonliving entities to pursue an analysis that is more appropriate for the genre at hand. Even though evolution will undoubtedly have predisposed our brains to be highly tuned to the difference between being alive or not (e.g., Caramazza \& Shelton, 1998), evolution has also equipped us with the capacity to acquire and express new concepts and ideas and to mentally pursue counterfactual "what if" simulations in order to anticipate future events (e.g., Fauconnier \& Turner, 2002). Perhaps as a side effect of this ability, we can apply modes of thinking to subject matters we were not designed for (Pinker, 1997). Mixing and matching our ways of understanding in fact seems to come pretty naturally to us, as we can easily-within the time frame of a few sentences-enter a world of fiction where yachts visit psychotherapists and peanuts fall in love. It is this flexibility that allows us to cope with, and even enjoy, stories that violate everything we know to be true in the real world.

\section{Acknowledgments}

We thank Jesse Jansen, Marte Otten, Petra van Alphen, Marcus Spaan, Bert Molenkamp, Geert-Jan Mertens, Thomas Koenig, and John Nagengast for their help. This research was supported by an NWO Innovation Impulse Vidi grant to J. V. B.

Reprint requests should be sent to Mante S. Nieuwland, Department of Psychology (PN), University of Amsterdam, Roetersstraat 15, 1018 WB Amsterdam, The Netherlands, or via e-mail: m.s.nieuwland@uva.nl.

\section{Notes}

1. Single- and two-step models of language interpretation also have their counterparts in the debate about interpretation of figurative expressions. It has been suggested that whereas literal language can be understood by normal linguistic mechanisms, listeners must recognize the deviant nature of a figurative utterance before determining its nonliteral meaning (e.g., Temple \& 
Honeck, 1999; Searle, 1979; Grice, 1975). However, this principled distinction between literal and contextualized meaning has been challenged by a number of researchers (e.g., Jackendoff, 2002; Clark, 1996; Gibbs, 1984).

2. The studies are also related in that both rely on the assumption that a highly problematic initial interpretation-from the perspective of the listener-would elicit a large N400 effect (in accordance with common assumptions about what the word-elicited N400 reflects; e.g., Brown, et al., 2000; Chwilla, Kolk, \& Mulder, 2000; Van Petten, Coulson, Rubin, Plante, \& Parks, 1999; Weckerly \& Kutas, 1999).

3. One subject reported to have consistently interpreted these anomalies as cases of reference transfer (i.e., a person that is called 'peanut'; Clark, 1996).

\section{REFERENCES}

Altmann, G. T. M., \& Kamide, Y. (1999). Incremental interpretation at verbs: Restricting the domain of subsequent reference. Cognition, 73, 247-264.

Barsalou, L. W. (1999). Perceptual symbol systems. Behavioral and Brain Sciences, 22, 577-660.

Bates, E., \& MacWhinney, B. (1989). Functionalism and the competition model. In E. Bates \& B. MacWhinney (Eds.), The crosslinguistic study of sentence processing. Cambridge: Cambridge University Press.

Brown, C. M., Hagoort, P., \& Kutas, M. (2000). Postlexical integration processes in language comprehension: Evidence from brain-imaging research. In M. S. Gazzaniga (Ed.), The cognitive neurosciences (2nd ed., pp. 881-895). Cambridge: MIT Press.

Caramazza, A., \& Shelton, J. R. (1998). Domain-specific knowledge systems in the brain: The animate-inanimate distinction. Journal of Cognitive Neuroscience, 10, $1-34$.

Carpenter, P. A., Miyake, A., \& Just, M. A. (1995). Language comprehension: Sentence and discourse processing. Annual Review of Psychology, 46, 91-100.

Chomsky, N. (1965). Aspects of the theory of syntax. Cambridge: MIT Press.

Chwilla, D. J., Kolk, H. H. J., \& Mulder, G. (2000). Mediated priming in the lexical decision task: Evidence from event-related potentials and reaction time. Journal of Memory and Language, 42, 314-341.

Clark, H. H. (1996). Using language. New York: Cambridge University Press.

Fauconnier, G., \& Turner, M. (2002). The way we think: Conceptual blending and the mind's hidden complexities. New York: Basic Books.

Fodor, J. A. (1983). The modularity of mind. Cambridge: MIT Press.

Forster, K. (1979). Levels of processing and the structure of the language processor. In: W. E. Cooper \& E. C. T. Walker (Eds.), Sentence processing: Psycholinguistic studies presented to Merrill Garrett. Hillsdale, NJ: Erlbaum.

Garnham, A. (1981). Mental models as representations of text. Memory and Cognition, 9, 560-565.

Gelman, S. A., \& Opfer, J. E. (2002). Development of the animate-inanimate distinction. In U. Goswami (Ed.), Blackwell handbook of childhood cognitive development (pp. 151-166). Malden, MA: Blackwell.

Gibbs, R. W. (1984). Literal meaning and psychological theory. Cognitive Science, 8, 275-304.

Graesser, A. C., Millis, K. K., \& Zwaan, R. A. (1997). Discourse comprehension. Annual Review of Psychology, 48, 163-189.
Grice, H. P. (1975). Logic and conversation. In P. Cole \& J. Morgan (Eds.), Syntax and semantics: Vol. 3, Speech acts. New York: Academic Press.

Hagoort, P., Hald, L., Bastiaansen, M., \& Petersson, K. M. (2004). Integration of word meaning and world knowledge in language comprehension. Science, 304, 438-441.

Hess, D. J., Foss, D. J., \& Carroll, P. (1995). Effects of global and local context on lexical processing during language comprehension. Journal of Experimental Psychology: General, 124, 62-82.

Jackendoff, R. (2002). Foundations of language: Brain, meaning, grammar, evolution. Oxford: Oxford University Press.

Johnson-Laird, P. N. (1983). Mental models: Towards a cognitive science of language, inference, and consciousness. Cambridge, MA: Harvard University Press.

Jones, D. (1999). Evolutionary psychology. Annual Review of Antbropology, 28, 553-575.

Jung, T. P., Makeig, S., Westerfield, M., Townsend, J., Courchesne, E., \& Sejnowski, T. J. (2000). Removal of eye activity artifacts from visual event-related potentials in normal and clinical subjects. Clinical Neurophysiology, 111, 1745-1758.

Katz, J. (1972). Semantic theory. New York: Harper \& Row. Kempson, R. (2001). Pragmatics: Language and communication. In M. Aronoff \& J. Rees-Miller (Eds.), Handbook of linguistics. Malden, MA: Blackwell.

Kintsch, W. (1988). The role of knowledge in discourse comprehension: A construction-integration model. Psychological Review, 95, 163-182.

Kutas, M., \& Hillyard, S. A. (1980). Reading senseless sentences: Brain potentials reflect semantic incongruity. Science, 207, 203-205.

Kutas, M., \& Van Petten, C. K. (1994). Psycholinguistics electrified: Event-related brain potential investigations. In M. A. Gernsbacher (Ed.), Handbook of psycholinguistics (pp. 83-143). San Diego, CA: Academic Press.

Lakoff, G. (1987). Women, fire, and dangerous things: What categories reveal about the mind. Chicago: University of Chicago Press.

Langacker, R. W. (1986). An introduction to cognitive grammar. Cognitive Science, 10, 1-40.

MacDonald, M. C., Pearlmutter, N. J., \& Seidenberg, M. S. (1994). The lexical nature of syntactic ambiguity resolution. Psychological Review, 101, 676-703.

Makeig, S., Jung, T.-P., Bell, A. J., \& Sejnowski, T. J. (1997). Blind separation of auditory event-related brain responses into independent components. Proceedings of the National Academy of Sciences, U.S.A., 94, 10979-10984.

Marslen Wilson, W., \& Tyler, L. K. (1980). The temporal structure of spoken language understanding. Cognition, 8, 1-71.

McKoon, G., \& Ratcliff, R. (1998). Memory-based language processing: Psycholinguistic research in the 1990s. Annual Review of Psychology, 49, 25-42.

Millis, K. K., \& Just, M. A. (1994). The influence of connectives on sentence comprehension. Journal of Memory and Language, 33, 128-147.

Münte, T. F., Schiltz, K., \& Kutas, M. (1998). When temporal terms belie conceptual order. Nature, 395, $71-73$.

Nieuwland, M. S., \& Van Berkum, J. J. A. (2005). Testing the limits of the semantic illusion phenomenon: ERPs reveal temporary change deafness in discourse comprehension. Cognitive Brain Research, 24, 691-701. 
Otten, M., \& Van Berkum, J. J. A. (2005). The influence of message-based predictability and lexical association on the N400 effect. Annual meeting of the Cognitive Neuroscience Society (CNS-2005), New York, April 9-12.

Pinker, S. (1997). How the mind works: New York: W. W. Norton.

Rayner, K., Pacht, J. M., \& Duffy, S. A. (1994). Effects of prior encounter and global discourse bias on the processing of lexically ambiguous words: Evidence from eye fixations. Journal of Memory and Language, 33, 527-544.

Rugg, M. D., \& Coles, M. G. H. (Eds.) (1995). Electrophysiology of mind: Event-related brain potentials and cognition. London: Oxford University Press.

Searle, J. (1979). Expression and meaning: Studies in the theory of speech acts. Cambridge, UK: Cambridge University Press.

Sedivy, J. C., Tanenhaus, M. K., Chambers, C. G., \& Carlson, G. N. (1999). Achieving incremental semantic interpretation through contextual representation. Cognition, 71, 109-147.

St. George, M., Mannes, S., \& Hoffman, J. E. (1994). Global semantic expectancy and language comprehension.

Journal of Cognitive Neuroscience, 6, 70-83.

St. George, M., Mannes, S., \& Hoffman, J. E. (1997). Individual differences in inference generation: An ERP analysis.

Journal of Cognitive Neuroscience, 9, 776-787.

Tanenhaus, M. K., Spivey Knowlton, M. J., Eberhard, K. M., \& Sedivy, J. C. (1995). Integration of visual and linguistic information in spoken language comprehension. Science, 268, 1632-1634.

Temple, J. G., \& Honeck, R. P. (1999). Proverb comprehension: The primacy of literal meaning. Journal of Psycholinguistic Research, 28, 41-70.

Till, R. E., Mross, E. F., \& Kintsch, W. (1988). Time course of priming for associate and inference words in a discourse context. Memory and Cognition, 16, 283-298.

Trueswell, J. C., \& Tanenhaus, M. K. (1994). Toward a lexicalist framework of constraint-based syntactic ambiguity resolution. In C. Clifton, Jr., L. Frazier, \& K. Rayner (Eds.), Perspectives on sentence processing (pp. 155-179). Hillsdale, NJ: Erlbaum.

Trueswell, J. C., \& Tanenhaus, M. K. (2005). Approaches to studying world-situated language use: Bridging the language-as-product and language-as-action traditions. Cambridge: MIT Press.
Trueswell, J. C., Tanenhaus, M. K., \& Garnsey, S. M. (1994). Semantic influences on parsing: Use of thematic role information in syntactic ambiguity resolution. Journal of Memory and Language, 33, 285-318.

Van Berkum, J. J. A. (2004). Sentence comprehension in a wider discourse: Can we use ERPs to keep track of things? In M. Carreiras \& C. Clifton, Jr. (Eds.), The on-line study of sentence comprehension: Eyetracking, ERPs and beyond (pp. 229-270). New York: Psychology Press.

Van Berkum, J. J. A. (in press). The electrophysiology of discourse and conversation. In M. Spivey, M. Joanisse, \& K. McRae (Eds.), The Cambridge handbook of psycholinguistics. Cambridge: Cambridge University Press.

Van Berkum, J. J. A., Brown, C. M., Zwitserlood, P., Kooijman, V., \& Hagoort, P. (2005). Anticipating upcoming words in discourse: Evidence from ERPs and reading times. Journal of Experimental Psychology: Learning, Memory, and Cognition, 31, 443-467.

Van Berkum, J. J. A., Hagoort, P., \& Brown, C. M. (1999). Semantic integration in sentences and discourse: Evidence from the N400. Journal of Cognitive Neuroscience, 11, 657-671.

Van Berkum, J. J. A., Zwitserlood, P., Hagoort, P., \& Brown, C. M. (2003). When and how do listeners relate a sentence to the wider discourse? Evidence from the N400 effect. Cognitive Brain Research, 17, 701-718.

Van Petten, C. (1995). Words and sentences: Event-related brain potential measures. Psychophysiology, 32, 511-525.

Van Petten, C., Coulson, S., Rubin, S., Plante, E., \& Parks, M. (1999). Time course of word identification and semantic integration in spoken language. Journal of Experimental Psychology: Learning, Memory, and Cognition, 25, 394-417.

Weckerly, J., \& Kutas, M. (1999). An electrophysiological analysis of animacy effects in the processing of objective relative sentences. Psychophysiology, 36, 559-570.

Wicha, N. Y. Y., Bates, E. A., Moreno, E. M., \& Kutas, M. (2003). Potato not Pope: Human brain potentials to gender expectation and agreement in Spanish spoken sentences. Neuroscience Letters, 346, 165-168.

Zwaan, R. A. (1994). Effect of genre expectations on text comprehension. Journal of Experimental Psychology: Learning, Memory, and Cognition, 20, 920-933.

Zwaan, R. A., \& Radvansky, G. A. (1998). Situation models in language comprehension and memory. Psychological Bulletin, 123, 162-185. 